\title{
Transcutaneous electrical nerve stimulation for advanced cancer pain inpatients in specialist palliative care-a blinded, randomized, sham-controlled pilot cross-over trial
}

\author{
Waldemar Siemens ${ }^{1}$ (D) $\cdot$ Christopher Boehlke ${ }^{1}$ (D) $\cdot$ Michael I. Bennett $^{2}$ (D) $\cdot$ Klaus Offner $^{3} \cdot$ Gerhild Becker $^{1}$ (D) \\ Jan Gaertner ${ }^{4}$ (D)
}

Received: 13 December 2019 / Accepted: 19 February 2020 / Published online: 3 March 2020

(C) The Author(s) 2020

\begin{abstract}
Purpose Transcutaneous electrical nerve stimulation (TENS) is a treatment option for cancer pain, but the evidence is inconclusive. We aimed to evaluate the efficacy and safety of TENS.

Methods A blinded, randomized, sham-controlled pilot cross-over trial (NCT02655289) was conducted on an inpatient specialist palliative care ward. We included adult inpatients with cancer pain $\geq 3$ on an 11-point numerical rating scale (NRS). Intensitymodulated high TENS (IMT) was compared with placebo TENS (PBT). Patients used both modes according to their preferred application scheme during $24 \mathrm{~h}$ with a $24-\mathrm{h}$ washout phase. The primary outcome was change in average pain intensity on the NRS during the preceding $24 \mathrm{~h}$. Responders were patients with at least a "slight improvement."

Results Of 632 patients screened, 25 were randomized (sequence IMT-PBT = 13 and PBT-IMT = 12). Finally, 11 patients in IMT-PBT and 9 in PBT-IMT completed the study $(N=20)$. The primary outcome did not differ between groups (IMT minus PBT: $-0.2,95 \%$ confidence interval -0.9 to 0.6$)$. However, responder rates were higher in IMT (17/20 [85\%] vs. 10/20 [50\%], $p=0.0428)$. Two patients experienced an uncomfortable feeling caused by the current, one after IMT and one after PBT. Seven patients (35\%) desired a TENS prescription. Women and patients with incident pain were most likely to benefit from TENS.

Conclusion TENS was safe, but IMT was unlikely to offer more analgesic effects than PBT. Even though many patients desired a TENS prescription, 50\% still reported at least "slight pain relief" from PBT. Differences for gender and incident pain aspects demand future trials.
\end{abstract}

Keywords Palliative care $\cdot$ Cancer pain $\cdot$ Non-pharmacological $\cdot$ Transcutaneous electrical nerve stimulation $\cdot$ Complementary therapies

Gerhild Becker and Jan Gaertner contributed equally to this study.

Electronic supplementary material The online version of this article (https://doi.org/10.1007/s00520-020-05370-8) contains supplementary material, which is available to authorized users.

Waldemar Siemens

waldemar.siemens@googlemail.com

1 Clinic for Palliative Care, Medical Center, Faculty of Medicine, University of Freiburg, Robert-Koch-Str 3, 79106 Freiburg, Germany

2 Academic Unit of Palliative Care, Leeds Institute of Health Sciences (LIHS), School of Medicine, University of Leeds, Leeds, UK

3 Department of Anesthesiology and Critical Care, Medical Center, Faculty of Medicine, University of Freiburg, Freiburg, Germany

4 Center for Palliative Care Hildegard, Basel, Switzerland

\section{Introduction}

Cancer pain is a leading symptom on palliative care units (ca. $80 \%$ of patients) [1,2]. As an adjunct to pharmacological cancer pain management, transcutaneous electrical nerve stimulation (TENS) is a safe, non-invasive, and inexpensive non-pharmacological option for pain treatment [3-5]. TENS is usually applied at the site of pain, where it stimulates large diameter (A- $\beta$ ) afferent fibers, which leads to a decreased activity of transmission cells and subsequently to reduced perception of pain according to the Gate-Control-Theory [6].

Though TENS is recommended in most palliative care and cancer pain textbooks [3, 4], controlled trials from a palliative care setting are lacking, what may be due to multimorbidity, recruitment barriers, high attrition rates, and general ethical difficulties [7]. In a Cochrane Review on TENS for cancer pain in 
adult patients, only three RCTs were identified [8]. Varying study designs, TENS modes, and outcome measures across studies as well as small sample sizes led to inconclusive results [9-11].

Therefore, the primary aim was to evaluate efficacy and safety of TENS in addition to standard care for advanced cancer pain patients. The secondary aim of this study was the exploratory identification of subgroups that do or do not benefit from TENS.

\section{Materials and methods}

\section{Study design and setting}

This was a blinded, randomized, sham-controlled pilot crossover trial (DRKS00007990; ClinicalTrials.gov Identifier NCT02655289). Patients were recruited from the inpatient specialist palliative care ward and the acute pain service of the University Medical Center Freiburg, Germany.

The study was approved by the local ethics committee in 2015. We report this manuscript in accordance with the Consolidated Standards of Reporting Trials (CONSORT) Statement's extension for non-pharmacological treatments (NPTs) (Online Resource 1) [12] and the Template for Intervention Description and Replication (TIDieR) checklist (Online Resource 2) [13].

\section{Participants}

We included adult inpatients $\geq 18$ years with cancer and pain $\geq 3$ on an 11-point numerical rating scale (NRS, $0=$ no pain; $10=$ pain as bad as you can imagine) in the preceding $24 \mathrm{~h}$. Pain could have been caused by the tumor itself (cancer pain), cancer-directed therapy, or by an association with the tumor, e.g., being bedridden or daily activities. Patients had to have received specialist palliative care for at least $24 \mathrm{~h}$ in the inpatient palliative care ward or by the acute pain service. There were no limitations concerning tumor site and type of cancer pain (neuropathic and nociceptive pain).

The exclusion criteria were verbal or cognitive inability to use TENS or to answer the questionnaire, high probability of dying within the next week according to the treating physician, and pain that was not directly or indirectly related to the tumor (i.e., chronic low back pain). In addition, we used the following TENS contraindications $[4,14]$ : electronic implants like pacemakers, metal implant on electrode site, arrhythmia, pregnancy, epilepsy, dermatological conditions or frail skin on electrode site, and history of allergy regarding electrodes or patches.

\section{Intervention: intensity-modulated high TENS}

A dual channel TENS device (ARTROSTIM ${ }^{\circledR}$ SELECT ${ }^{\mathrm{TM}}$, ORMED) was used at the site of pain in the intervention
(IMT) and placebo TENS (PBT) phase. Patients were instructed by an experienced researcher who received training and supervision of a senior physician. The intervention used intensity-modulated TENS (IMT) with $100 \mathrm{~Hz}$. The patients were advised to choose a "strong but comfortable" intensity $[5,15]$ and the intensity was modulated automatically with a decrease of $40 \%$ every $0.5 \mathrm{~s}$ in order to prevent habituation [16].

IMT and PBT were used by patients individually, i.e., they were free to turn TENS on or off as they pleased, according to their own perceived benefit.

\section{Comparison: Placebo TENS}

PBT, or sham-controlled TENS, was based on the continuous mode with $100 \mathrm{~Hz}$ and a fixed intensity, which was either slightly or not perceptible at all. For the sake of adequate blinding, we instructed the patients that two active TENS modes were compared. Patients were informed that the TENS device could be turned on according to individual needs and that the sensory threshold would probably not be reached in this TENS mode. The TENS device was activated for PBT with an intensity that was mostly perceptible for a few seconds and then fell below the sensory threshold through habituation. The display and flashing light of the device in the PBT mode looked and behaved exactly as in the IMT mode [17].

\section{Outcomes}

Most outcomes were based on the Brief Pain Inventory (BPI) $[18,19]$ and were chosen with consideration to recommendations for pain assessment $[17,20]$.

The primary outcome was change of mean pain intensity in the preceding $24 \mathrm{~h}$, measured on an 11-point NRS before and after the 24-h IMT or PBT phase and after the flexible followup.

Secondary outcomes of the BPI over the $24 \mathrm{~h}$ period included change of worst pain intensity, change of least pain intensity, and BPI items that may have been affected by pain: general activity, mood, walking ability, normal work, relations with other people, sleep, and enjoyment of life. Some outcomes were measured on other scales: change of pain perception during TENS application on a 7-point verbal rating scale (VRS), number and percentage of responders defined as patients with at least a "slight improvement" on the abovementioned 7-point VRS. Question 30 from the European Organization for Research and Treatment of Cancer quality of life questionnaire C30 (EORTC QLQC30) [21] was used to assess quality of life.

Medication with an influence on pain (opioids, nonopioids, antidepressants, anticonvulsants) was documented at baseline and during the study, i.e., if a new drug was added 
or removed, or if the dose of a drug was increased or decreased by $>50 \%$ [22]. Furthermore, the oral morphine equivalent dose (MED) was calculated. Pain classification was assessed with the Edmonton Classification System for Cancer Pain [23] and the Douleur Neuropathique en 4 Questions (DN4) [24].

\section{Study procedure}

The patients were screened by treating physicians in the inpatient palliative care ward and the acute pain service. Eligible patients were contacted by the study team to obtain informed consent for study participation. A senior physician was responsible for the randomization list, enabled a concealed central allocation, and patients were directly randomized after giving informed consent. Randomization was performed according to a random, computer-generated list with an allocation ratio of 1:1.

The senior physician was not involved in the provision of the intervention or data assessment. TENS was started immediately after allocation to the sequence, and patients were instructed that two active TENS modes were compared in this study.

Patients, researchers, the outcome assessor, and the biometrician were blinded concerning the mode of intervention. Thus, the researcher placed the electrodes without knowing the TENS mode. TENS was subsequently activated (IMT or PBT) by a non-blinded treating physician who was not involved in the data collection, data analysis, or the preparation of the manuscript. Patients were instructed not to tell anything about their perceptions of the TENS mode to the research team and had to turn off the TENS device during answering the questionnaire.

Patients used the first TENS mode during the first 24-h phase (period 1). After the $24 \mathrm{~h}$ washout phase, the patient crossed over to the other TENS mode for another $24 \mathrm{~h}$ (period 2). After the main part of the study (period 1 and period 2), patients could decide whether to continue with one of the TENS modes (IMT or PBT) for a flexible short-term followup or to stop the study (see study design: Online Resource 3).

\section{Statistical analysis}

We aimed to include 20 patients in this pilot trial to assess the effects and safety (primary aim), and gather valuable information for a fully powered multicenter study. This cross-over trial was analyzed according the recommendations by Wellek and Blettner [25] and Li et al. [26]. Unpaired $t$ tests of the withinsubject sums of the result from both periods were used to check carry-over effects ( $p \geq 0.05$ : carry-over effect is negligible) [25]. Paired $t$ tests were calculated for within-subject differences of change scores from both periods ( $\mathrm{t} 2$ minus $\mathrm{t} 1$, or $\mathrm{t} 4$ minus t3, see Online Resource 3). As sensitivity analysis, paired $t$ tests were also calculated for within-subject differences of post treatment scores from both periods ( $\mathrm{t} 2$, t4), according to the recommendations by Li et al. [26]. Numbers of responders were compared with the help of the chi-squared test.

As subgroup analysis (secondary aim), we explored characteristics from patients that benefited or did not benefit from TENS regarding average pain intensity in the preceding $24 \mathrm{~h}$. Benefit was defined as difference of more than minus one for change scores (primary outcome) and post treatment scores when subtracting IMT minus PBT, and/or change scores within groups (IMT, PBT) of more than minus one on the NRS [27].

Patients with complete data for period 1 and period 2 were analyzed per-protocol [28] and were evaluated irrespective of how often or how long they used the TENS modes.

All tests for the secondary outcomes were exploratory. The tests were performed two-tailed using an alpha level of 0.05 . The statistical analysis was performed using R (RStudio Version 3.4.2) [29].

\section{Results}

\section{Screening and patient inclusion}

Participants were recruited from February 2016 to February 2018. We screened 632 patients on the inpatient palliative care ward (see Fig. 1). Most of the patients $(591 / 632,93.5 \%)$ were not eligible (Fig. 1). Twenty-five of $41(61.0 \%)$ eligible patients were randomized. Eleven patients in IMT-PBT and 9 in PBT-IMT completed the study $(N=20)$.

The dropout analysis is presented in detail in Online Resource 4. It shows that six of the 26 recruited patients (23.1\%) were dropouts, one of them dropped out after signing informed consent but before randomization (see Fig. 1). These dropped out patients tended to have a higher Eastern Cooperative Oncology Group (ECOG) level and higher average pain levels before receiving PBT: 3.35 (standard deviation [SD] 1.35) vs. 5.25 (SD 0.5). The other variables were, for the most part, balanced.

Most patients $(15 / 20,75 \%)$ stopped the study after completing both sequences and were not available for the shortterm follow-up, e.g., because of the burden in using TENS $(5 / 15,33 \%)$ or no perceived effect $(3 / 15,20 \%)$ (see Online Resource 5).

\section{Baseline characteristics}

Table 1 shows the baseline characteristics in both sequences. Most characteristics were well balanced. Slight differences between both sequences were observed in cancer entity, ECOG, and DN4. Average pain at baseline was lower in the IMT-PBT than in the PBT-IMT sequence and, within the IMTPBT sequence, lower in PBT than in IMT (see Table 1). 
Regular medication intake before randomization intervention was comparable between sequences (Online Resource 6). The oral MED per day had slightly higher means and SDs in the IMT-PBT sequence. Opioid, non-opioid, antidepressant, and anticonvulsant intake was equally distributed between IMT-PBT and PBT-IMT. None of these drugs were decreased by $>50 \%$ of the dose or removed during the trial. In IMT, increasing or adding drugs was not necessary. In PBT, some drugs had to be added or increased by $>50 \%$ of the dose: nonopioid 2/20 (10\%), antidepressant $1 / 20(5 \%)$, and anticonvulsant $1 / 20(5 \%)$.

\section{Duration of TENS use}

In sequence IMT-PBT, patients used TENS for $10.6 \mathrm{~h}$ (SD 8.3) in IMT and for 5.7 h (SD 5.0) in PBT based on the record from the TENS device. In contrast, the TENS use in sequence PBT-IMT was $7.1 \mathrm{~h}$ (SD 6.3) in IMT and $8.4 \mathrm{~h}$ (SD 6.2) in PBT. In total, TENS was used for $9.1 \mathrm{~h}$ (SD 7.5) in IMT and for $7.0 \mathrm{~h}$ (SD 5.6) in PBT during the 24-h period ( $p=0.3340$; $n=17$; three missing values) (Online Resource 7).

\section{Difference between groups}

Table 2 shows the change scores in periods, sequences, and the total for analyzing differences between the IMT and PBT phase in the primary and secondary outcomes.

The differences of IMT minus PBT for each sequence were rather small and none of them were statistically significant in this pilot trial. The results of the change scores were consistent with the sensitivity analysis of post treatment scores (Online Resource 8) [26].

Figure 2a and $b$ illustrates each participant's change score and post treatment score, respectively, that were used to compare IMT and PBT (negative values favor IMT).

The change of pain perception during the TENS application is shown in Table 3. Seventeen out of 20 patients (85\%) had at least a "slight improvement" on the 7-point VRS (responder criterion) during IMT and 10/20 (50\%) during the PBT phase $(p=0.0428)$.

\section{Difference within groups}

The analysis of changes within IMT indicated that patients experienced a decrease in average pain, worst pain, least pain, mood, walking ability, and relations (Table 4). In PBT, comparable changes were observed for average pain and worst pain but not for any of the other outcomes (Online Resource 9).

Figure 2 gives an overview of the change within groups for the primary outcome. Both IMT (Fig. 2c) and PBT (Fig. 2d) clearly included more negative change scores with slightly more decrease in average pain for IMT.

\section{Safety: TENS-related adverse events}

One out of $20(5 \%)$ patients perceived the electric current as uncomfortable after the IMT phase and 1/20 (5\%) after the PBT phase. No other TENS-related adverse events were reported. Four patients $(20 \%)$ generally criticized that cables were impractical and one $(5 \%)$ patient felt disturbed by the electrodes.

After testing both TENS modes, 7/20 (35\%) patients requested a prescription for the TENS device in order to use TENS after discharge.

\section{Explorative subgroup analysis}

Online Resources 10,11, 12, and 13 show the core outcomes for mean pain intensity (see Fig. 2), which were analyzed with regard to the patients' benefit. Four patients in the change score comparison (Online Resource 10), one patient in the post treatment comparison (Online Resource 11), seven patients in the change within IMT comparison (Online Resource 12), and five patients in the change within PBT comparison (Online Resource 13) experienced a benefit, defined as difference or change of more than minus one on the NRS (see also Fig. 2). Taking the baseline values in Table 1 into account, descriptive comparisons indicated that females and patients suffering from incident pain were probably more likely to benefit from IMT although the sample sizes of these comparisons were very small (Online Resource 10, Online Resource 12). The explorative subgroup analysis did not indicate differences between patients with neuropathic and non-neuropathic pain.

\section{Discussion}

\section{Summary of main findings}

With regard to change in average pain intensity (primary outcome), we observed no differences between IMT and PBT. However, results indicated higher responder rates for IMT as secondary outcome. TENS was safe and well accepted.

\section{Difference between groups}

There were no statistically significant differences between groups. These findings are supported by other RCTs, which evaluated TENS in cancer patients [9-11]. However, neither our study nor the other RCTs were powered to detect small effects between groups. In contrast, a recent, powered crossover RCT with 40 head and neck cancer patients identified clinically relevant effects favoring active TENS compared with PBT and no TENS for resting pain [27, 30-32]. In this trial, the outcomes were assessed before and directly after 
Fig. 1 Flow diagram

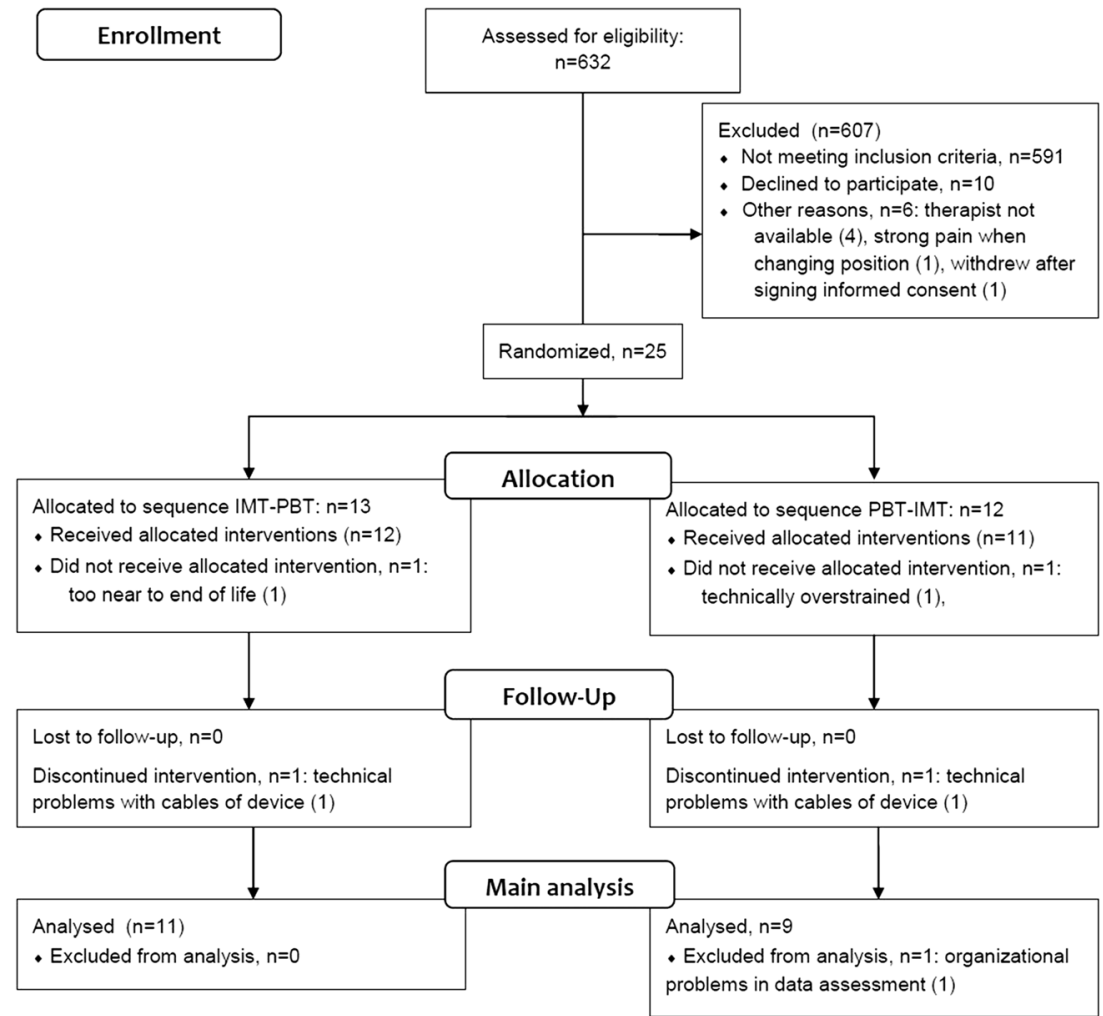

30 min of TENS. Change scores were compared among three TENS conditions (active TENS with $125 \mathrm{~Hz}$, PBT, no TENS) and seven outcomes resulting in 21 statistical tests, which raises the question of a multiple testing problem in this analysis [33].

Interestingly, our results indicate that IMT had more responders than PBT as measured on the 7-point VRS (responder criterion: at least a "slight improvement") for change of pain perception during TENS application. This important finding is strengthened by another cross-over RCT, in which the authors also observed a difference between active TENS and PBT on the VRS but not on the NRS scale [9]. Therefore, a 7-point VRS for pain relief might be more responsive than an 11-point NRS for assessing TENS in short period interventions [9].

\section{Difference within groups}

In IMT, the items worst pain, mood, walking ability, and relations showed a mean change of one or more on an 11-point NRS in the IMT phase, which was suggested as clinically relevant [30]. Additionally, the mean changes of IMT in least pain, mood, walking ability, and relations may also be clinically relevant for individual patients, i.e., a change of two points or more on an 11-point NRS or a pain relief of $33 \%$ or more [27]. The change in walking ability for IMT underpins the idea that TENS may be helpful to reduce movementrelated pain $[9,15]$.
For PBT, only changes in average pain and worst pain were observed. Similar to IMT, the changes in average pain were slightly below the threshold of clinical relevance as explained above $[27,30]$. However, the change of $-1.6(95 \% \mathrm{CI}-2.7$ to -0.4 ) in worst pain in the PBT phase can be considered clinically relevant [30].

Comparable changes within groups were also reported in other RCTs for average pain and worst pain [11], pain at rest $[9,31]$ or at movement [9], and fatigue [31].

The results underline that different outcome measures should be assessed since reduced pain perception could result in increased activity levels implying changes in physical function and psycho-social outcomes [10, 15].

\section{TENS-related adverse events}

With regard to safety, IMT was well accepted and safe in this study. These results are comparable with the analysis of another RCT [9]. The six dropped out patients tended to have a higher ECOG level and higher average pain levels before receiving $\mathrm{PBT}$. The other variables were balanced or hard to judge because of the low number of dropouts. The safety of TENS was not explicitly measured in some RCTs [10, 11, 31] but authors referred to TENS as safe method. A usability problem rather than a safety problem was the fact that the main reason for stopping the study after period 2 was the burden in using TENS $(5 / 15,33 \%)$, e.g., because of the disturbing cables of the device (see Online Resource 5 for further reasons). 
Table 1 Baseline characteristics

\begin{tabular}{|c|c|c|}
\hline & Sequence IMT-PBT: $N=11$ & Sequence PBT-IMT: $N=9$ \\
\hline Age, mean (SD) & $58.3(16.2)$ & $59.2(9.4)$ \\
\hline \multicolumn{3}{|l|}{ Sex } \\
\hline Male & $4(36.4 \%)$ & $4(44.4 \%)$ \\
\hline Female & $7(63.6 \%)$ & $5(55.6 \%)$ \\
\hline BMI, mean (SD) & $23.6(6.5)$ & $23.5(4.1)$ \\
\hline \multicolumn{3}{|l|}{ ECOG } \\
\hline 1 & $0(0.0 \%)$ & $0(0.0 \%)$ \\
\hline 2 & $7(63.6 \%)$ & $3(33.3 \%)$ \\
\hline 3 & $4(36.4 \%)$ & $6(66.7 \%)$ \\
\hline 4 & $0(0.0 \%)$ & $0(0.0 \%)$ \\
\hline \multicolumn{3}{|l|}{ Primary tumor } \\
\hline Lung-Ca & $3(27.3 \%)$ & $2(22.2 \%)$ \\
\hline Pancreas-Ca & $2(18.2 \%)$ & $0(0.0 \%)$ \\
\hline Mamma-Ca & $0(0.0 \%)$ & $1(11.1 \%)$ \\
\hline Prostate-Ca & $0(0.0 \%)$ & $1(11.1 \%)$ \\
\hline Rectum-Ca & $1(9.1 \%)$ & $0(0.0 \%)$ \\
\hline Miscellaneous & $5(45.5 \%)$ & $5(55.6 \%)$ \\
\hline \multicolumn{3}{|l|}{ TENS position } \\
\hline Lower limb & $1(9.1 \%)$ & $0(0.0 \%)$ \\
\hline Lumbar spine & $3(27.3 \%)$ & $2(22.2 \%)$ \\
\hline Pelvis & $2(18.2 \%)$ & $2(22.2 \%)$ \\
\hline Ribs & $4(36.4 \%)$ & $1(11.1 \%)$ \\
\hline Scapula & $0(0.0 \%)$ & $1(11.1 \%)$ \\
\hline Thoracic spine & $1(9.1 \%)$ & $3(33.3 \%)$ \\
\hline \multicolumn{3}{|l|}{ Radiation (not in TENS area) } \\
\hline Yes & $2(18.2 \%)$ & $2(22.2 \%)$ \\
\hline No & $9(81.8 \%)$ & $7(77.8 \%)$ \\
\hline \multicolumn{3}{|l|}{ DN4 score } \\
\hline DN4 $<4$ & $8(72.7 \%)$ & $4(44.4 \%)$ \\
\hline DN4 $\geq 4$ & $3(27.3 \%)$ & $5(55.6 \%)$ \\
\hline \multicolumn{3}{|l|}{ ECP mechanism of pain } \\
\hline Nociceptive: visceral and/or bone or soft tissue & $6(54.5 \%)$ & $4(44.4 \%)$ \\
\hline Neuropathic with or without nociceptive pain & $5(45.5 \%)$ & $5(55.6 \%)$ \\
\hline \multicolumn{3}{|l|}{ ECP incident pain } \\
\hline Yes & $10(90.9 \%)$ & $7(77.8 \%)$ \\
\hline No & $1(9.1 \%)$ & $2(22.2 \%)$ \\
\hline \multicolumn{3}{|l|}{ ECP psychological distress } \\
\hline Yes & $9(81.8 \%)$ & $7(77.8 \%)$ \\
\hline No & $2(18.2 \%)$ & $1(11.1 \%)$ \\
\hline Insufficient information to classify & $0(0.0 \%)$ & $1(11.1 \%)$ \\
\hline \multicolumn{3}{|l|}{ Non-physical effects on pain ("total pain") } \\
\hline No effect & $1(9.1 \%)$ & $0(0.0 \%)$ \\
\hline Small effect & $6(54.5 \%)$ & $4(44.4 \%)$ \\
\hline Moderate effect & $3(27.3 \%)$ & $2(22.2 \%)$ \\
\hline Large effect & $1(9.1 \%)$ & $3(33.3 \%)$ \\
\hline Large effect & $0(0.0 \%)$ & $0(0.0 \%)$ \\
\hline Average pain before treatment IMT, mean (SD) & $3.5(1.0)$ & $4.2(0.8)$ \\
\hline Average pain before treatment $\mathrm{PBT}$, mean (SD) & $2.6(1.2)$ & $4.2(1.0)$ \\
\hline
\end{tabular}

$B M I$, body mass index; DN4, Douleur Neuropathique en 4 Questions; $E C O G$, Eastern Cooperative Oncology Group; ECP, Edmonton Classification System for Cancer Pain; IMT, intensity-modulated high TENS; NRS, numerical rating scale; PBT, placebo TENS; SD, standard deviation; TENS, transcutaneous electrical nerve stimulation

DN4 score: range $0-10$ : higher score $=$ greater neuropathic pain $(\geq 4$ cutoff value for neuropathic pain $)$

ECOG: range $0-5.0=$ Fully active, able to carry on all pre-disease performance without restriction; $1=$ restricted in physically strenuous activity but ambulatory and able to carry out work of a light or sedentary nature, e.g., light house work, office work; 2 = ambulatory and capable of all self-care but unable to carry out any work activities, up and about more than $50 \%$ of waking hours; $3=$ capable of only limited self-care, confined to bed or chair more than $50 \%$ of waking hours; $4=$ completely disabled, cannot carry on any self-care, totally confined to bed or chair; $5=$ dead $($ Oken et al., 1982$)$

NRS for average pain: $0=$ no pain or no interference; $10=$ worst imaginable pain or maximum interference 


\section{Gender aspects and incident pain}

Among all benefit subgroup analyses, we believe that two findings are noteworthy even though the results were descriptive and the sample size was very small.

Gender In palliative care and in the field of cancer pain management, gender issues are currently becoming increasingly recognized and future research in this area is advocated [34-36]. Interestingly, in our trial, women were more likely to report improvement from TENS. This could be a result of recently discussed sex differences regarding testosterone and estrogen levels as well as T cells and immune cells and their role in pain perception. However, most findings were based on animal models [37]. To the best of our knowledge, we are unaware of previous TENS RCTs in cancer pain reporting a gender differences in benefit subgroup analysis.
Incident pain In the field of cancer pain, incident cancer pain has been identified as a condition with room for improvement in terms of the available treatment options [38]. Therefore, it should be noted that in our study, patients with incident cancer pain were more likely to experience benefit under TENS, which has not been assessed in previous TENS trials in palliative care [8]. A reason for this finding might be that demonstrating a change was easier in patients with increased pain scores than in the comparatively low baseline pain scores of patients without incident pain [9].

\section{Strengths}

The strength of this study is the cross-over design that allowed patients to be their own control and have a balance of covariates [9]. The generalizability can be considered high because of the wide inclusion criteria, no artificial changes in patients' medication plans, and the possibility of an individual use of

Table 2 Differences between groups. Change scores in periods, sequences, and total (IMT-PBT: $N=11$; PBT-IMT: $N=9$; total: $N=20$ )

\begin{tabular}{|c|c|c|c|c|c|c|}
\hline Outcome & Sequence & $\begin{array}{l}\text { Period } 1 \\
\text { Mean (SD) }\end{array}$ & $\begin{array}{l}\text { Period } 2 \\
\text { Mean (SD) }\end{array}$ & $\begin{array}{l}\text { IMT minus PBT } \\
\text { Mean of differences (SD) }\end{array}$ & $\begin{array}{l}\text { Total IMT minus PBT } \\
\text { Mean of differences }(95 \% \mathrm{CI})\end{array}$ & $p$ value* \\
\hline $\begin{array}{l}\text { Average pain } \\
\text { NRS: } 0-10\end{array}$ & $\begin{array}{l}\text { IMT-PBT } \\
\text { PBT-IMT }\end{array}$ & $\begin{array}{l}-0.8(1.0) \\
-1.2(1.5)\end{array}$ & $\begin{array}{l}-0.4(1.0) \\
-1.0(1.4)\end{array}$ & $\begin{array}{r}-0.5(1.4) \\
0.2(1.6)\end{array}$ & $-0.2(-0.9$ to 0.6$)$ & 0.6590 \\
\hline $\begin{array}{l}\text { Worst pain } \\
\text { NRS: } 0-10\end{array}$ & $\begin{array}{l}\text { IMT-PBT } \\
\text { PBT-IMT }\end{array}$ & $\begin{array}{l}-1.4(1.7) \\
-1.8(3.1)\end{array}$ & $\begin{array}{l}-1.4(2.1) \\
-1.2(1.3)\end{array}$ & $\begin{array}{l}0.0(2.6) \\
0.6(3.6)\end{array}$ & $0.3(-1.1$ to 1.6$)$ & 0.7125 \\
\hline $\begin{array}{l}\text { Least pain } \\
\text { NRS: } 0-10\end{array}$ & $\begin{array}{l}\text { IMT-PBT } \\
\text { PBT-IMT }\end{array}$ & $\begin{array}{l}-0.5(1.1) \\
-0.7(1.4)\end{array}$ & $\begin{array}{l}-0.4(1.2) \\
-1.0(0.9)\end{array}$ & $\begin{array}{l}-0.1(2.0) \\
-0.3(1.7)\end{array}$ & $-0.2(-1.1$ to 0.7$)$ & 0.6295 \\
\hline $\begin{array}{l}\text { Quality of life } \\
\text { Scale: } 1-7\end{array}$ & $\begin{array}{l}\text { IMT-PBT } \\
\text { PBT-IMT }\end{array}$ & $\begin{array}{l}0.7(1.4) \\
0.9(1.4)\end{array}$ & $\begin{array}{r}0.1(1.3) \\
-0.1(1.2)\end{array}$ & $\begin{array}{r}0.6(2.0) \\
-1.0(1.7)\end{array}$ & -0.1 ( -1.0 to 0.8$)$ & 0.8252 \\
\hline $\begin{array}{l}\text { General activity } \\
\text { NRS: } 0-10\end{array}$ & $\begin{array}{l}\text { IMT-PBT } \\
\text { PBT-IMT }\end{array}$ & $\begin{array}{l}-1.0(3.2) \\
-1.2(4.0)\end{array}$ & $\begin{array}{l}-1.5(2.6) \\
-1.9(2.9)\end{array}$ & $\begin{array}{r}0.5(4.5) \\
-0.7(5.1)\end{array}$ & $0.0(-2.2$ to 2.2$)$ & 1.0000 \\
\hline $\begin{array}{l}\text { Mood } \\
\text { NRS: } 0-10\end{array}$ & $\begin{array}{l}\text { IMT-PBT } \\
\text { PBT-IMT }\end{array}$ & $\begin{array}{r}0.0(3.3) \\
-2.1(3.9)\end{array}$ & $\begin{array}{l}-0.5(2.9) \\
-2.0(1.7)\end{array}$ & $\begin{array}{l}0.5(3.9) \\
0.1(4.1)\end{array}$ & $0.3(-1.5$ to 2.1$)$ & 0.7351 \\
\hline $\begin{array}{l}\text { Walking ability } \\
\text { NRS: } 0-10\end{array}$ & $\begin{array}{l}\text { IMT-PBT } \\
\text { PBT-IMT }\end{array}$ & $\begin{array}{l}-1.8(3.9) \\
-2.3(3.7)\end{array}$ & $\begin{array}{r}0.4(2.1) \\
-1.8(2.2)\end{array}$ & $\begin{array}{r}-2.2(4.5) \\
0.6(3.5)\end{array}$ & $-1.0(-2.9$ to 1.0$)$ & 0.3229 \\
\hline $\begin{array}{l}\text { Normal work } \\
\text { NRS: } 0-10\end{array}$ & $\begin{array}{l}\text { IMT-PBT } \\
\text { PBT-IMT }\end{array}$ & $\begin{array}{l}-2.7(3.6) \\
-2.6(3.1)\end{array}$ & $\begin{array}{r}0.6(2.9) \\
-2.0(2.1)\end{array}$ & $\begin{array}{r}-3.4(5.5) \\
0.6(3.8)\end{array}$ & $-1.6(-4.0$ to 0.8$)$ & 0.1745 \\
\hline $\begin{array}{l}\text { Relations } \\
\text { NRS: } 0-10\end{array}$ & $\begin{array}{l}\text { IMT-PBT } \\
\text { PBT-IMT }\end{array}$ & $\begin{array}{l}0.7(2.7) \\
0.0(1.7)\end{array}$ & $\begin{array}{r}0.1(1.9) \\
-1.7(1.3)\end{array}$ & $\begin{array}{r}0.6(3.6) \\
-1.7(2.1)\end{array}$ & $-0.4(-1.9$ to 1.1$)$ & 0.5790 \\
\hline $\begin{array}{l}\text { Sleep } \\
\text { NRS: } 0-10\end{array}$ & $\begin{array}{l}\text { IMT-PBT } \\
\text { PBT-IMT }\end{array}$ & $\begin{array}{l}-1.0(2.3) \\
-1.7(4.0)\end{array}$ & $\begin{array}{r}0.7(3.0) \\
-1.3(2.2)\end{array}$ & $\begin{array}{r}-1.7(3.1) \\
0.3(3.9)\end{array}$ & $-0.8(-2.5$ to 0.9$)$ & 0.3279 \\
\hline $\begin{array}{l}\text { Enjoyment of life } \\
\text { NRS: } 0-10\end{array}$ & $\begin{array}{l}\text { IMT-PBT } \\
\text { PBT-IMT }\end{array}$ & $\begin{array}{l}-0.1(4.0) \\
-1.7(3.2)\end{array}$ & $\begin{array}{r}0.0(2.2) \\
-1.8(1.4)\end{array}$ & $\begin{array}{l}-0.1(5.1) \\
-0.1(3.5)\end{array}$ & $-0.1(-2.1$ to 1.9$)$ & 0.9185 \\
\hline
\end{tabular}

EORTC QLQ-C30, European Organization for Research and Treatment of Cancer quality-of-life questionnaire core 30; IMT, intensity-modulated high TENS; NRS, numerical rating scale; $P B T$, placebo TENS; SD, standard deviation; TENS, transcutaneous electrical nerve stimulation

NRS items adapted from the Brief Pain Inventory: $0=$ no pain or no interference; $10=$ worst imaginable pain or maximum interference; quality of life scale: 1 = very poor, 7 = excellent

Sequence IMT-PBT, $N=11$; sequence PBT-IMT, $N=9$; total, $N=20$; quality of life was measured with the EORTC QLQ-C30 quality of life item; item "Pain relief with TENS" not listed: provides only post treatment values

* $p$ value testing difference between treatments: paired $t$ test of within-subject differences of pre-post change scores from both periods; $p$ values $<0.05$ : statistically significant difference between treatments ( $\mathrm{Li}$ et al., 2015); checking carry-over effect: unpaired $t$ test of within-subject sums of the result from both periods: all $p$ values were $\geq 0.05$ : carry-over effect is negligible (Wellek \& Blettner, 2012) 
a Differences between groups: Change scores

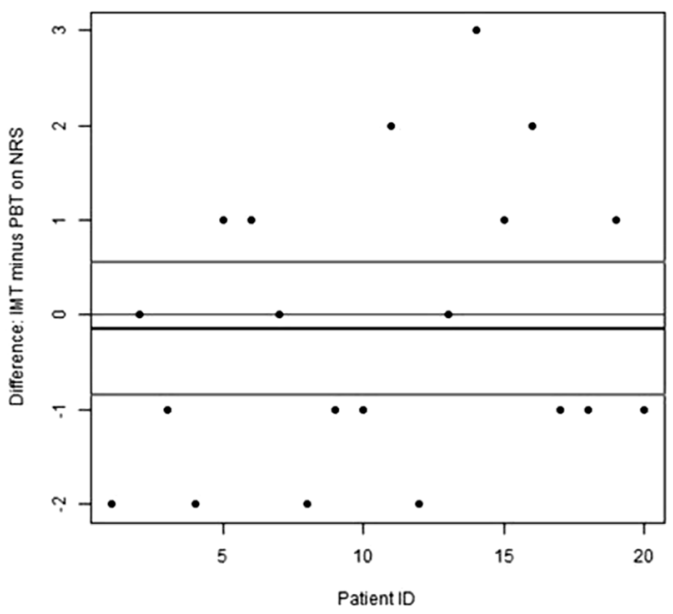

C Change scores within treatment IMT

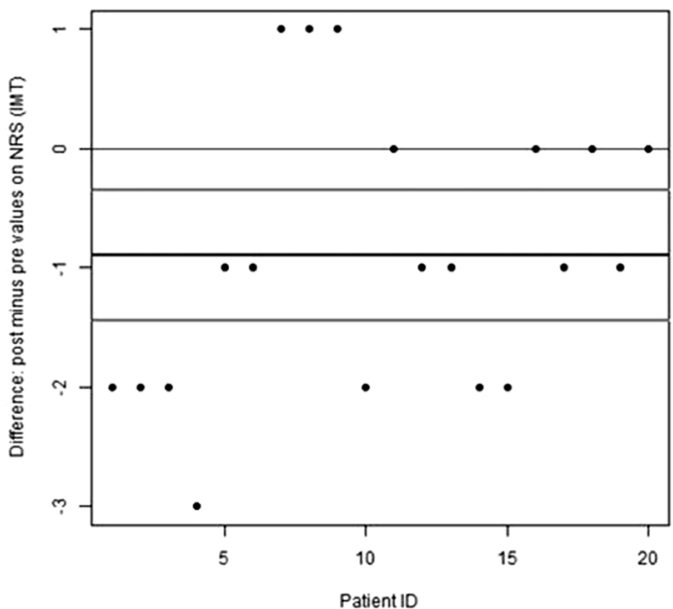

Fig. 2 Graphical analysis of pain mean intensity. a Change scores (primary outcome). b Post treatment scores. c Change scores within IMT. d Change scores within PBT. IMT, intensity-modulated high TENS; NRS, numerical rating scale; PBT, placebo TENS. Negative

TENS. The latter could also have had a positive impact on self-efficacy of the included cancer patients [39].

Table 3 Change on verbal rating scale $(N=20)$

\begin{tabular}{lll}
\hline Category & IMT & PBT \\
\hline Very clear deterioration & $0(0 \%)$ & $1(5 \%)$ \\
Clear deterioration & $0(0 \%)$ & $0(0 \%)$ \\
Slight deterioration & $0(0 \%)$ & $0(0 \%)$ \\
No change & $2(10 \%)$ & $7(35 \%)$ \\
Slight improvement & $13(65 \%)$ & $9(45 \%)$ \\
Clear improvement & $3(15 \%)$ & $1(5 \%)$ \\
Very clear improvement & $1(5 \%)$ & $0(0 \%)$ \\
Not applicable; no pain the last $24 \mathrm{~h}$ & $1(5 \%)$ & $2(10 \%)$ \\
\hline
\end{tabular}

$I M T$, intensity-modulated high TENS; $P B T$, placebo TENS b Difference between groups: Post treatment scores

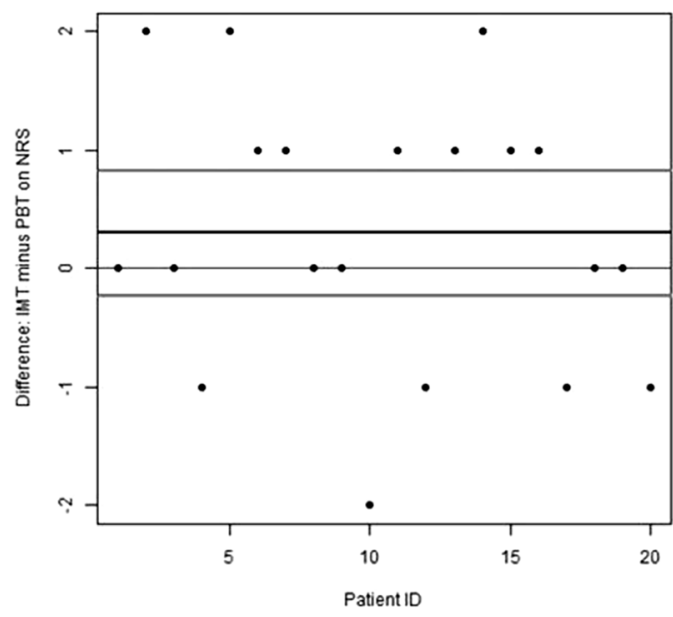

d Change scores within treatment PBT

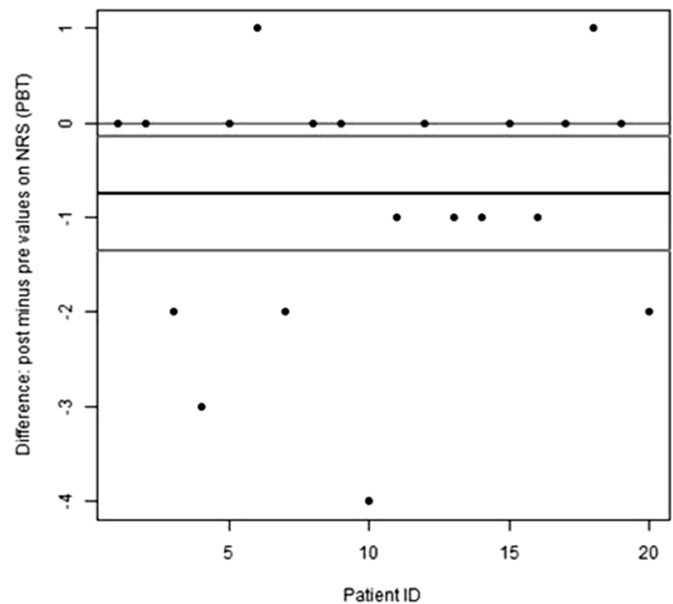

values in a and $\mathbf{b}$ favor IMT; negative values in $\mathbf{c}$ favor IMT or in $\mathbf{d}$ PBT. Thin black line, null or no effect; dark gray line, mean of differences; light gray line, 95\% confidence interval of paired $t$ test ( $\mathrm{Li}$ et al., 2015)

Though the washout phase of other RCTs [9-11, 31] differed from our trial, we are still confident that our study design and its washout phase was appropriate due to the absence of carry-over effects and washouts of $20-30 \mathrm{~min}$ that are considered adequate in literature [4, 40, 41].

Also, we considered methodological recommendations for clinical trials evaluating TENS for pain treatment that covered the domains allocation, application, and assessment [17]. Accordingly, sources of bias based on the Cochrane's risk of bias tool for RCTs were thoroughly considered [42].

Finally, RCT data concerning TENS from the specialist palliative care setting is extremely scarce. Our study showed that using TENS was feasible in patients with advanced cancer on an inpatient palliative care ward. It provides valuable data on efficacy and safety, and hereby enhances the evidence base of TENS for advanced cancer patients. 
Table 4 Change scores within treatment IMT $(N=20)$

\begin{tabular}{|c|c|c|c|c|}
\hline Outcome & Pre mean (SD) & Post mean (SD) & Post-pre difference $(95 \% \mathrm{CI})$ & $p$ value* \\
\hline Average pain & $3.8(1.0)$ & $2.9(1.2)$ & $-0.9(-1.4$ to -0.4$)$ & 0.0027 \\
\hline $\begin{array}{l}\text { NRS: } 0-10 \\
\text { Worst pain }\end{array}$ & $6.0(1.7)$ & $4.7(2.2)$ & $-1.3(-2.0$ to -0.6$)$ & 0.0010 \\
\hline $\begin{array}{l}\text { NRS: } 0-10 \\
\text { Least pain }\end{array}$ & $2.2(1.4)$ & $1.5(1.3)$ & $-0.7(-1.2$ to -0.2$)$ & 0.0068 \\
\hline $\begin{array}{l}\text { NRS: } 0-10 \\
\text { Pain relief with TENS }\end{array}$ & $4.3(1.5)$ & $4.7(0.9)$ & $0.4(-0.3$ to 1.0$)$ & 0.2601 \\
\hline $\begin{array}{l}\text { Scale: } 0-100 \% \\
\text { Quality of life }\end{array}$ & $4.9(1.8)$ & $3.5(2.4)$ & $-1.4(-2.8$ to 0.0$)$ & 0.0529 \\
\hline $\begin{array}{l}\text { Scale: } 0-7 \\
\text { General activity }\end{array}$ & $4.6(2.2)$ & $3.7(2.6)$ & $-0.9(-2.2$ to 0.4$)$ & 0.1707 \\
\hline $\begin{array}{l}\text { NRS: } 0-10 \\
\text { Mood }\end{array}$ & $4.5(2.6)$ & $2.7(2.4)$ & $-1.8(-3.3$ to -0.3$)$ & 0.0206 \\
\hline $\begin{array}{l}\text { NRS: } 0-10 \\
\text { Walking ability }\end{array}$ & $5.7(2.3)$ & $3.3(2.2)$ & $-2.4(-3.8$ to -1.0$)$ & 0.0017 \\
\hline $\begin{array}{l}\text { NRS: } 0-10 \\
\text { Normal work }\end{array}$ & $2.9(2.3)$ & $2.6(2.3)$ & $-0.4(-1.5$ to 0.8$)$ & 0.5314 \\
\hline $\begin{array}{l}\text { NRS: 0-10 } \\
\text { Relations }\end{array}$ & $3.3(2.5)$ & $2.1(2.1)$ & $-1.2(-2.2$ to -0.1$)$ & 0.0310 \\
\hline $\begin{array}{l}\text { NRS: 0-10 } \\
\text { Sleep }\end{array}$ & $4.6(2.7)$ & $3.7(3.0)$ & $-0.9(-2.3$ to 0.6$)$ & 0.2399 \\
\hline NRS: $0-10$ & & & & \\
\hline
\end{tabular}

EORTC QLQ-C30, European Organization for Research and Treatment of Cancer quality-of-life questionnaire core 30; IMT, intensity-modulated high TENS; NRS, numerical rating scale; SD, standard deviation; TENS, transcutaneous electrical nerve stimulation

NRS items adapted from the Brief Pain Inventory: $0=$ no pain or no interference; $10=$ worst imaginable pain or maximum interference. Pain relief: $0 \%=$ no pain relief; $100 \%=$ maximum pain relief. Quality of life scale: $1=$ very poor, $7=$ excellent

* $p$ value of paired $t$ test testing difference within treatment IMT

\section{Limitations}

A shortcoming of this study is that effects may have been underestimated because the pain intensity was low at baseline and outcomes were not measured during the peak effect of TENS, i.e., immediately after stopping TENS [15]. The responder definition in this trial was pre-specified in the protocol (NCT02655289) and based on the VRS. However, a responder definition based on the NRS was found more appropriate for patients' chronic pain conditions [43].

Most patients had some sensation during the PBT phase and patients were told that two active TENS modes were compared. This may have led to the considerable effects within the PBT phase and, consequently, to small differences between groups. A third group, e.g., no TENS, could have been of help for assessing the possibly large placebo effect. In general, it should be considered that only a minority of the screened patients on the inpatient palliative care ward was eligible $(41 / 632,6.5 \%)$.

For the sake of generalizability, we included patients with various types of cancer, sites of pain and types of pain, which enhanced heterogeneity of the sample. In contrast to trials assessing pain therapy in chronic non-cancer pain conditions [44], the primary outcome in palliative cancer pain trials is probably more influenced by progress and instability of the disease that may have further contributed to the heterogeneity and variance in the results.

We closely followed the study protocol (NCT02655289). There were only two minor deviations: no block randomization and no recruitment via palliative care consultant service (see Online Resource 14).

We abstained from imputing missing data to enable an intention-to-treat-analysis because of the small sample and the pilot character of this trial [45]. Therefore, the results on efficacy and safety of TENS for advanced cancer pain patients, and especially the subgroup analyses, need to be interpreted cautiously and take into account that a type 2 error cannot be excluded.

\section{Conclusion}

TENS was safe, but IMT was unlikely to offer more analgesic effects than PBT. As secondary outcomes, we found higher 
responder rates for IMT than for PBT and mean changes within both groups that may be clinically relevant for patients especially in the IMT group. Even though many patients desired to continue TENS therapy after the end of the study, 50\% of the patients still reported at least "slight pain relief" from PBT. These results should be interpreted cautiously due to the per-protocol analysis and the small sample size of this trial, especially in the subgroup analyses. Nevertheless, we suggest that differences for gender and incident pain aspects should be further investigated in future trials.

Acknowledgments We thank Marga Hauck, Jolanda Daniuk, Michael Mueller, Carolin Aurnhammer, and Alexa Heeg for their help in recruiting patients and Carolin Jenkner for her advice in methodological questions. We are indebted to all patients who participated in this study.

Authors' contributions Conception and design: Siemens, W; Becker, G; Gaertner J

Collection and assembly of data: Siemens, W; Boehlke, C

Analysis of data: Siemens, W

Interpretation of results: All authors

Manuscript writing: Siemens W. (first draft); Gaertner, J

Final approval of manuscript: All authors

All authors discussed the results and commented on the manuscript.

Funding information Open Access funding provided by Projekt DEAL. This work is supported by internal resources of the Clinic for Palliative Care, Department of Internal Medicine, University Medical Center Freiburg, Germany.

Data The corresponding author has full control of all primary data. Primary data is available on request.

\section{Compliance with ethical standards}

The study was approved by the local ethics committee on December 23, 2016.

Conflict of interest The authors declare that they have no conflict of interest.

Open Access This article is licensed under a Creative Commons Attribution 4.0 International License, which permits use, sharing, adaptation, distribution and reproduction in any medium or format, as long as you give appropriate credit to the original author(s) and the source, provide a link to the Creative Commons licence, and indicate if changes were made. The images or other third party material in this article are included in the article's Creative Commons licence, unless indicated otherwise in a credit line to the material. If material is not included in the article's Creative Commons licence and your intended use is not permitted by statutory regulation or exceeds the permitted use, you will need to obtain permission directly from the copyright holder. To view a copy of this licence, visit http://creativecommons.org/licenses/by/4.0/.

\section{References}

1. Radbruch L, Nauck F, Ostgathe C, Elsner F, Bausewein C, Fuchs M, Lindena G, Neuwöhner K, Schulenberg D (2003) What are the problems in palliative care? Results from a representative survey. Support Care Cancer 11(7):442-451

2. Worldwide Palliative Care Alliance (2014) Global atlas of palliative care at the end of life. Available at: http://www.thewhpca.org/ resources/global-atlas-on-end-of-life-care Accessed December 12, 2014

3. Franklin AE, Lovell MR (2019) Pain and pain management. In: MacLeod RD, van den Block L (eds) Textbook of palliative care. Springer International Publishing, Cham

4. Disselhoff B (2012) TENS - Transkutane Elektrische Nervenstimulation in der onkologischen Schmerztherapie. In: Bernatzky G, Sittl R, Likar R (eds) Schmerzbehandlung in der Palliativmedizin. 3. Auflage, 3rd edn. Springer, Wien, p 241

5. Vance CGT, Dailey DL, Rakel BA, Sluka KA (2014) Using TENS for pain control: the state of the evidence. Pain Manag 4(3):197209

6. Melzack R, Wall PD (1965) Pain mechanisms: a new theory. Science 150(3699):971-979

7. Visser C, Hadley G, Wee B (2015) Reality of evidence-based practice in palliative care. Cancer Biol Med 12(3):193-200

8. Hurlow A, Bennett MI, Robb KA et al (2012) Transcutaneous electric nerve stimulation (TENS) for cancer pain in adults. Cochrane Database Syst Rev 3:1-27

9. Bennett MI, Johnson MI, Brown SR, Radford H, Brown JM, Searle RD (2010) Feasibility study of transcutaneous electrical nerve stimulation (TENS) for cancer bone pain. J Pain 11(4):351-359

10. Gadsby JG, Franks A, JPDF (1997) Acupuncture-like transcutaneous electrical nerve stimulation within palliative care: a pilot study. Complement Ther Med 5:13-18

11. Robb KA, Di Newham J, Williams JE (2007) Transcutaneous electrical nerve stimulation vs. transcutaneous spinal electroanalgesia for chronic pain associated with breast cancer treatments. J Pain Symptom Manag 33(4):410-419

12. Boutron I, Altman DG, Moher D et al (2017) CONSORT statement for randomized trials of nonpharmacologic treatments: a 2017 update and a CONSORT extension for nonpharmacologic trial abstracts. Ann Intern Med 167(1):40-47

13. Hoffmann TC, Glasziou PP, Boutron I et al (2014) Better reporting of interventions: template for intervention description and replication (TIDieR) checklist and guide. BMJ 348:g1687

14. Jones I, Johnson MI (2009) Transcutaneous electrical nerve stimulation. Contin Educ Anaesth Crit Care Pain 9(4):130-135

15. Sluka KA, Bjordal JM, Marchand S, Rakel BA (2013) What makes transcutaneous electrical nerve stimulation work? Making sense of the mixed results in the clinical literature. Phys Ther 93(10):13971402

16. Johnson MI (2014) Transcutaneous electrical nerve stimulation (TENS): research to support clinical practice, 1st edn. Oxford University Press, New York

17. Bennett MI, Hughes N, Johnson MI (2011) Methodological quality in randomised controlled trials of transcutaneous electric nerve stimulation for pain: low fidelity may explain negative findings. PAIN 152(6):1226-1232

18. Furler L (2013) Validität und Reliabilität des Schmerzfragebogens "Brief pain inventory". Eine Literaturrecherche. Pflege Z 66(9): 546-550. https://pubmed.ncbi.nlm.nih.gov/?term $=\% 22 \mathrm{Pflege}+Z \%$ $22 \% 5$ Bjournal\% $\% \mathrm{D}$

19. Radbruch L, Loick G, Kiencke P, Lindena G, Sabatowski R, Grond S, Lehmann KA, Cleeland CS (1999) Validation of the German version of the brief pain inventory. J Pain Symptom Manag 18(3): $180-187$

20. Dworkin RH, Turk DC, Farrar JT, Haythornthwaite JA, Jensen MP, Katz NP, Kerns RD, Stucki G, Allen RR, Bellamy N, Carr DB, Chandler J, Cowan P, Dionne R, Galer BS, Hertz S, Jadad AR, Kramer LD, Manning DC, Martin S, McCormick C, McDermott M, McGrath P, Quessy S, Rappaport BA, Robbins W, Robinson JP, 
Rothman M, Royal MA, Simon L, Stauffer JW, Stein W, Tollett J, Wernicke J, Witter J, IMMPACT (2005) Core outcome measures for chronic pain clinical trials: IMMPACT recommendations. PAIN 113(1-2):9-19

21. Aaronson NK, Ahmedzai S, Bergman B, Bullinger M, Cull A, Duez NJ, Filiberti A, Flechtner H, Fleishman SB, de Haes JC (1993) The European Organization for Research and Treatment of Cancer QLQ-C30: a quality-of-life instrument for use in international clinical trials in oncology. J Natl Cancer Inst 85(5):365-376

22. Mücke M, Tils M, Conrad R, Kravchenko D, Cuhls H, Radbruch L, Marinova M, Peuckmann-Post V, Rolke R (2018) Matrix stimulation in cancer pain: methodology, safety and effectiveness. Eur $\mathbf{J}$ Pain 22(1):58-71

23. Nekolaichuk CL, Fainsinger RL, Aass N, Hjermstad MJ, Knudsen AK, Klepstad P, Currow DC, Kaasa S, European Palliative Care Research Collaborative (EPCRC) (2013) The Edmonton Classification System for Cancer Pain: comparison of pain classification features and pain intensity across diverse palliative care settings in eight countries. J Palliat Med 16(5):516-523

24. Bouhassira D, Attal N, Alchaar H, Boureau F, Brochet B, Bruxelle J, Cunin G, Fermanian J, Ginies P, Grun-Overdyking A, JafariSchluep H, Lantéri-Minet M, Laurent B, Mick G, Serrie A, Valade D, Vicaut E (2005) Comparison of pain syndromes associated with nervous or somatic lesions and development of a new neuropathic pain diagnostic questionnaire (DN4). PAIN 114(1-2): 29-36

25. Wellek S, Blettner M (2012) On the proper use of the crossover design in clinical trials: part 18 of a series on evaluation of scientific publications. Dtsch Arztebl Int 109(15):276-281

26. Li T, Yu T, Hawkins BS et al (2015) Design, analysis, and reporting of crossover trials for inclusion in a meta-analysis. PLoS One 10(8)

27. Farrar JT, Berlin JA, Strom BL (2003) Clinically important changes in acute pain outcome measures: a validation study. J Pain Symptom Manag 25(5):406-411

28. Sedgwick P (2013) What is per protocol analysis? BMJ 346(jun14 1):f3748-f3748

29. R Core Team. R: a language and environment for statistical computing. Vienna, Austria. Available at: https://www.R-project.org/. Accessed 26 Feb 2020

30. Hui D, Shamieh O, Paiva CE, Perez-Cruz PE, Kwon JH, Muckaden MA, Park M, Yennu S, Kang JH, Bruera E (2015) Minimal clinically important differences in the Edmonton Symptom Assessment Scale in cancer patients: a prospective, multicenter study. Cancer 121(17):3027-3035

31. Lee JE, Anderson CM, Perkhounkova Y et al (2018) Transcutaneous electrical nerve stimulation reduces resting pain in head and neck cancer patients: a randomized and placebocontrolled double-blind pilot study. Cancer Nurs
32. Farrar JT, Young JP, LaMoreaux L et al (2001) Clinical importance of changes in chronic pain intensity measured on an 11-point numerical pain rating scale. PAIN 94(2):149-158

33. Ranganathan P, Pramesh CS, Buyse M (2016) Common pitfalls in statistical analysis: the perils of multiple testing. Perspect Clin Res 7(2):106-107

34. Hansen MB, Ross L, Petersen MA et al (2019) Age, cancer site and gender associations with symptoms and problems in specialised palliative care: a large, nationwide, register-based study. BMJ Support Palliat Care

35. Planelles B, Margarit C, Inda M-d-M et al (2019) Gender based differences, pharmacogenetics and adverse events in chronic pain management. Pharmacogenomics J 43:983

36. Wagner AD, Oertelt-Prigione S, Adjei A et al (2019) Gender medicine and oncology: report and consensus of an ESMO workshop. Ann Oncol

37. Dance A (2019) Why the sexes don't feel pain the same way. Nature 567(7749):448-450

38. Mercadante S, Portenoy RK (2016) Breakthrough cancer pain: twenty-five years of study. Pain 157(12):2657-2663

39. Kreitler S, Peleg D, Ehrenfeld M (2007) Stress, self-efficacy and quality of life in cancer patients. Psychooncology 16(4):329-341

40. Chesterton LS, Foster NE, Wright CC et al (2003) Effects of TENS frequency, intensity and stimulation site parameter manipulation on pressure pain thresholds in healthy human subjects. Pain 106(1-2): $73-80$

41. Andersson SA, Hansson G, Holmgren E, Renberg O (1976) Evaluation of the pain suppressive effect of different frequencies of peripheral electrical stimulation in chronic pain conditions. Acta Orthop Scand 47(2):149-157

42. Higgins JPT, Green S. Cochrane handbook for systematic reviews of interventions. Version 5.1.0 2011. Available at: http://handbook. cochrane.org/ Accessed March 24, 2015

43. Dworkin RH, Turk DC, Peirce-Sandner S et al (2010) Research design considerations for confirmatory chronic pain clinical trials: IMMPACT recommendations. PAIN 149(2):177-193

44. Gibson W, Wand BM, Meads C et al (2019) Transcutaneous electrical nerve stimulation (TENS) for chronic pain-an overview of Cochrane Reviews. Cochrane Database Syst Rev 4:CD011890

45. Hollis S, Campbell F (1999) What is meant by intention to treat analysis? Survey of published randomised controlled trials. BMJ 319(7211):670-674

Publisher's note Springer Nature remains neutral with regard to jurisdictional claims in published maps and institutional affiliations. 